\title{
Clinical Syndromes and Associations with Persistent Pulmonary Hypertension of the Newborn
}

\author{
Jae H. Kim and Anup Katheria \\ Division of Neonatal-Perinatal Medicine, Department of Pediatrics \\ University of California San Diego \\ United States of America
}

\section{Introduction}

Persistent pulmonary hypertension of the newborn (PPHN) occurs when the normal cardiopulmonary transition fails to occur. In term infants, PPHN is thought to occur in 2 per 1000 infants, and in approximately 10 percent of infants with respiratory failure. PPHN is a significant source of morbidity and mortality in this population. Early identification of infants with PPHN is difficult because it is the failure of the newborn to lower its pulmonary pressure and vascular resistance over time that must occur in order to make the diagnosis. However, it is imperative for the clinician to identify the newborn with clinical features that may be associated with PPHN since making the clinical diagnosis of a genetic syndrome or association can considerably alter the overall prognosis of the infant.

The transitional period from fetus to newborn is marked by changes in blood flow that are necessary for the newborn to adapt to an extrauterine environment. During fetal circulation, blood flows across the fetal channels, namely the foramen ovale (FO) and the patent ductus arteriosus (PDA), largely bypassing the pulmonary circuit. Although the pulmonary vascular surface area increases during fetal development, pulmonary vascular resistance also increases with gestational age when corrected for body weight, suggesting that pulmonary vascular tone increases during late gestation. After birth, pulmonary blood flow increases dramatically due to a decrease in pulmonary vascular resistance (PVR), which occurs at a variable rate. During birth, critical signals are necessary for the normal rapid fall in PVR to occur, mainly mechanical distension of the lung, a decrease in carbon dioxide tension, and an increase in oxygen tension in the lung. If these signals do not occur the vascular resistance will stay elevated and the result is PPHN.

Typically PPHN is caused by abnormally constricted vasculature as a result of diseased lung parenchyma from pneumonia or meconium aspiration syndrome. However, there are other congenital causes of PPHN that can lead to persistently constricted vasculature without lung disease. Other congenital causes of PPHN can result from a remodeled pulmonary vasculature or hypoplastic vasculature that is often associated with maldeveloped or underdeveloped lungs. 
In this review, we will highlight genetic abnormalities that result in abnormalities of pulmonary vasculature that cause PPHN. Importantly, we will first review the normal development of the lung to contextualize the varied presentations of PPHN. PPHN in genetically normal infants has a mortality of 5-10 percent and about $25 \%$ of infants with moderate to severe PPHN will exhibit significant neurodevelopmental impairment at 12 to 24 month (Steinhorn, 2010). This group may dramatically differ from infants with congenital causes of PPHN in that there may be a higher mortality and risk for neurodevelopmental impairment in certain anomalies. The ability to identify theses infants early in their clinical course is essential for providing timely counseling to parents and determining whether medical therapy may be beneficial. We will also highlight any of the phenotypic features of congenital syndromes that may assist the clinician in diagnosis.

\subsection{Normal lung development}

The development of the respiratory system entails both structural development of the lung and lung maturation in order to have normal lung function (Burri, 2006). Lung development occurs during fetal growth in five phases. The embryonic period occurs when the lung first appears as a ventral bud off the esophagus. The lung bud then elongates to form the two mainstem bronchi. Subsequent branching gives rise to the conducting airways. Lobar segments are found by 37 days that then progress to segmental airways by 42 days and further division into subsegmental bronchi by 48 days. The pulmonary vasculature branches off the sixth aortic arch to form a vascular plexus within the mesenchymal of the lung bud. Many of the severe and global tracheal and pulmonary abnormalities occur during this early embryogenesis period.

The second stage involves further branching of about 15 to 20 generations of the airways and occurs during the $7^{\text {th }}$ to $18^{\text {th }}$ week of gestation. This stage is called the pseudoglandular stage. There is some epithelial differentiation that occurs with the appearance of ciliated cells, goblet cells and basal cells. Pulmonary arteries grow in conjunction with the airways with the principal arterial pathways being present by 14 weeks. Pulmonary venous development occurs in parallel but with a different pattern that demarcates lung segments and subsegments. By the end of the pseudoglandular stage, airways arteries and veins are similar at least in pattern to an adult.

The third stage is the cannalicular stage that occurs between 16 and 25 weeks gestation. This represents the transformation of the pre-viable lung to the viable lung that can exchange gas (Zeltner \& Burri, 1987). The three major changes that occur during this stage are the appearance of the alveolar air sacs, epithelial differentiation with the appearance of an air-

blood barrier, and the presence of surfactant secreting type II cells. The formation of a capillary network to occur in tandem with saccular branching is critical for air exchange. Failure for this to occur can result in alveolar-capillary dysplasia.

The fourth and fifth stages of lung development are the saccular and alveolar stages, respectively. The saccular stage encompasses the period of development from 25 weeks until term. The saccular stage involves the terminal or distal airway that elongates branches and widens until alveolarization is complete. Alveolarization is initiated in the terminal saccules by the appearance of septa in association with capillaries, elastin fibers, and collagen fibers. Alveoli are increasing in number with the most rapid increase from 32 weeks gestation until the first few months after term delivery. New alveoli continue to form until 7-8 years of age. 


\subsection{Purpose of in utero respiratory movements}

Fetal lung fluid is essential for normal lung development. The fetal lung fluid flows up the trachea with fetal breathing movements and a higher pressure in the trachea compared to the amniotic fluid is maintained. This allows a continuously positive outflow of lung fluid and maintenance of lung volume despite high pressures from the surrounding amniotic fluid. The lung is therefore a net secretory organ. The fetal lung fluid maintains a larger lung volume than the normal functional residual capacity of the lung. Animal data have demonstrated that distension of the fetal lung by fluid leads to hyperplasia of the lung while drainage of the fluid leads to pulmonary hypoplasia (Moessinger, Harding, Adamson, Singh, \& Kiu, 1990).

In the human fetus, breathing movements are noted as early as 11 weeks of gestation and by $30-40$ weeks, it occurs about $30 \%$ of the time. Decreased fetal breathing can lower the tracheal pressures allowing lung volume to decrease and result in secondary pulmonary hypoplasia. Abolishing fetal breathing movements in animal experiments by either ablation of the phrenic nerve or spinal cord transection result in pulmonary hypoplasia (Fewell, Lee, \& Kitterman, 1981; Wigglesworth, 1981). Increase in carbon dioxide and glucose levels, acidosis and drugs such as caffeine and theophylline are associated with increased fetal breathing movements. Maternal smoking, alcohol and drug use are known to reduce fetal breathing movements.

In the last decade there have been a number of advances in research on fetal tracheal occlusion to maintain fetal lung volume and stretching lung tissue to improve lung growth. A number of animal studies have demonstrated that surgical tracheal occlusion applied during the canalicular and saccular stages of lung development not only improves dry lung weight but also increases airway branching, alveolarization, alveolar surface area, type II pneumocytes and pulmonary vascular growth (Khan, Cloutier, \& Piedboeuf, 2007).

\section{Major physiological causes of pulmonary hypertension}

\subsection{Developmental disorders of the lung}

Successful lung growth during gestation requires differentiation and branching with development of the pulmonary parenchyma, cartilage and pulmonary vessels all of which are necessary for a successful transition. A number of growth factors, platelet derived growth factors, and vascular endothelial growth factors are required to ensure proper development of pulmonary parenchyma many of which are concurrently assisting the development of the pulmonary vasculature. Therefore when there are abnormalities apparent in the pulmonary parenchyma, one can assume that the pulmonary vessels in the affected lung are also affected resulting in increase pulmonary vascular resistance. In this section we will review the spectrum of lower airway anomalies including pulmonary agenesis/aplasia, congenital cystic adenomatoid malformations, primary pulmonary hypoplasia, secondary pulmonary hypoplasia, and congenital diaphragmatic hernia.

\subsubsection{Primary pulmonary hypoplasia}

Primary pulmonary hypoplasia $(\mathrm{PH})$ is the underdevelopment of the pulmonary parenchyma of one or both lungs. Pulmonary hypoplasia refers to conditions when the bronchial tree and pulmonary parenchyma are present but with decreased size and number 
of the airway alveoli and pulmonary vessels present. Pulmonary hypoplasia includes a spectrum of problems which includes hypoplasia, aplasia, or agenesis of selected or all lung segments. The lesions may be lobar, unilateral, or bilateral. Some degree of the pulmonary hypoplasia spectrum is reported in 7 to $26 \%$ of all neonatal autopsies (Abudu, Uguru, \& Olude, 1988; Aghabiklooei, Goodarzi, \& Kariminejad, 2009). Primary pulmonary hypoplasia is rare and is often felt to be sporadic. The etiology and pathogenesis is unknown. It may be caused by an embryologic defect of the lung or vascular tissues or an in utero vascular accident. However, most cases of pulmonary hypoplasia are secondary to conditions that limit fetal lung growth (Correia-Pinto, Gonzaga, Huang, \& Rottier, 2010). Secondary causes of pulmonary hypoplasia are much more common than primary forms of pulmonary hypoplasia. These include oligohydramnios, thoracic dysplasia or thoracic space occupying lesions. In a series of 77 cases of pulmonary hypoplasia only 10 were felt to be primary (Page \& Stocker, 1982).

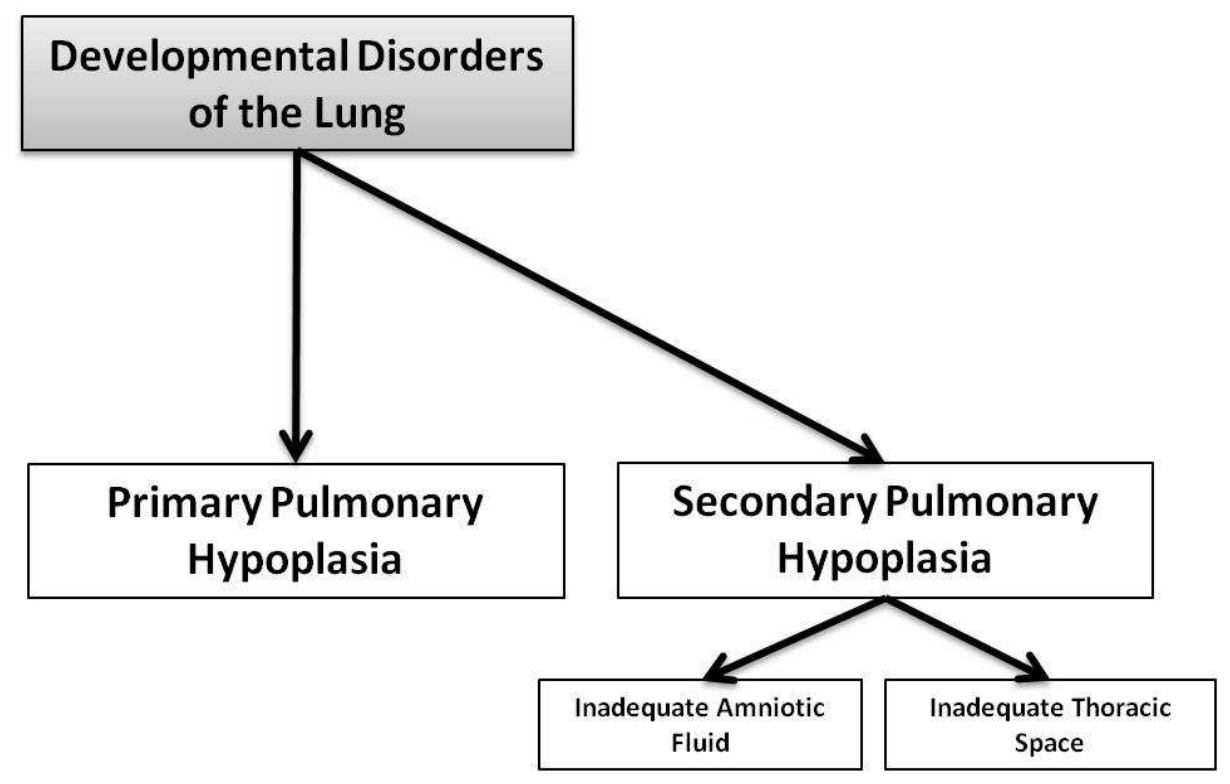

\section{Developmental Disorders Of Pulmonary Vasculature}

Other Pulmonary

Hypertension Causes

\section{Inborn Errors}

Fig. 1. Categories of causes of PPHN 


\subsubsection{Pulmonary agenesis/aplasia}

A rare cause of pulmonary hypoplasia is pulmonary agenesis in which there is unilateral or bilateral absence of the bronchus, pulmonary parenchyma or pulmonary vasculature. Pulmonary aplasia refers to presence of the bronchial tree without development of the parenchyma or pulmonary vasculature. Pulmonary agenesis is typically unilateral in about $70 \%$ of cases and bilateral agenesis is lethal at birth. Since unilateral agenesis can be isolated but often presents with other cardiovascular, vertebral, facial urogenital and/or gastrointestinal syndromes. A recent review of 269 cases of pulmonary agenesis from 1937 to 1997 highlighted that 60 had anomalies of the first and second branchial arches and/or radial ray defects (Cunningham \& Mann, 1997). As a consequence, pulmonary agenesis has been considered to be a part of the VACTERL association (Cunningham \& Mann, 1997; Knowles, Thomas, Lindenbaum, Keeling, \& Winter, 1988).

The VACTERL association is an acronym for a condition that includes vertebral defects, anal atresia, cardiac defects, and tracheoesophageal fistula with esophageal atresia, renal dysplasia, and limb defects. VACTERL association is not in itself a diagnosis but a nonrandom association of defects. As such it can be seen as a sporadic occurrence in an otherwise normal family and is more frequently seen in infants born to diabetic mothers (Kallen, Mastroiacovo, Castilla, Robert, \& Kallen, 2001). Although many of these patient may have failure to thrive and have some mild delay in early infancy related to their defects, the majority have normal neurodevelopmental outcomes and thus should receive full attempts towards rehabilitation. A phenotypically similar disorder referred to as VACTERL with hydrocephalus due to aqueductal stenosis has been reported and has both autosomal and X-linked recessive inheritance. These infants generally have a poor prognosis in most cases (Evans, Stranc, Kaplan, \& Hunter, 1989).

Fryns syndrome displays diaphragmatic abnormalities, coarse facies and distal hypoplasia, and has been reported to have a high incidence $(60 \%)$ of abnormal lung lobulations including pulmonary agenesis (Fryns, Moerman, Goddeeris, Bossuyt, \& Van den Berghe, 1979). Cystic hygroma of the neck is commonly seen on prenatal ultrasounds with the majority delivering stillborn or dying in the early neonatal period. Survival without severe neurodevelopmental impairment has not been reported. All affected individuals have coarse facies and distal digital hypoplasia usually represented by hypoplastic to absent nails and short terminal phalanges.

Hydrolethalus syndrome, also known as the combination of hydrocephalus, micrognathia, and polydactyly commonly has a variety of pulmonary defects including abnormal lung lobulation, malformed or hypoplastic pharynx, with a stenotic or abnormally dilated trachea. The pregnancies of these individuals are complicated by polyhydramnios and intrauterine growth restriction. About $70 \%$ are stillborn with live born infants usually surviving a few hours. The disorder has an autosomal recessive inheritance pattern and the defect is found on chromosome 11q23-25.

Pallister-Hall syndrome (PHS) features hypothalamic hamartoblastoma, hypopituitarism, imperforate anus, and postaxial polydactyly (Hall et al., 1980). Infants with PHS can have either pulmonary aplasia or pulmonary agenesis with abnormal lung lobulation. The majority die before age 3 , where the most common cause of death in the newborn period is hypoadrenalism (Jones \& Smith, 2006). If there are long-term survivors they typically need 
L-thyroxine, growth hormone, and corticosteroids from an early age as well as glucose infusions in the neonatal period. The disorder is transmitted in an autosomal dominant inheritance pattern and so a family history is critical. Mutations of GLI3 on 7p13 is responsible for this disorder (Narumi et al., 2010).

Other causes of pulmonary agenesis can occur in conjunction with diaphragmatic agenesis in which either one or both sides of the diaphragm fail to develop. Typically infants with both have associated heart defects, skin tags that are often found on the nares, and in females are found to have a hypoplastic uterus.

Tetraamelia syndrome is characterized by amelia (absence) of all four limbs with agenesis or hypoplasia of the lungs. They often have peripheral pulmonary vessel hypoplasia and death during the neonatal period is common. Other reported findings include low set ears, micrognathia, cleft lib and hydrocephalus. The condition appears to be inherited in an autosomal recessive pattern.

Smith-Lemli-Opitz syndrome (SLOS) has a constellation of features including abnormal pulmonary lobulation such as those with pulmonary agenesis with accompanying severe PPHN. Other key features of SLOS include anteverted nostrils, ptosis of eyelids, syndactyly of the second and third toes, and in males, hypospadias and cryptorchidism (also see 2.1.3.2 Smith-Lemli-Opitz syndrome).

\subsubsection{Secondary pulmonary hypoplasia}

Secondary $\mathrm{PH}$ is much more common than primary $\mathrm{PH}$ and can occur from a number of fetal and maternal abnormalities. The two most common cause of secondary $\mathrm{PH}$ are conditions in which there is inadequate amniotic fluid or insufficient space in the chest for normal lung development to occur.

\subsubsection{Inadequate amniotic fluid}

Typically the fetus is buoyant in amniotic fluid from 11 weeks gestation to term. Early lung maturation and development depends on the ability of the fetus to have respiratory chest and diaphragmatic effort with excursion of the chest and abdomen. In mid-gestation this involves the exchange of lung fluid and amniotic fluid in and out of the lung to accommodate these activities. The inability to generate such respiratory exercise leads directly to underdevelopment of the lung parenchymal and pulmonary hypoplasia.

\subsection{Renal agenesis}

One of the most common phenotypes of pulmonary hypoplasia is the Potter sequence in which the fetus' face is distorted and the chest is bell-shaped. Any condition that results in severe oligohydramnios can cause the phenotype if it is prolonged and severe. The most severe would be the lack of production of amniotic fluid from renal agenesis. The physical features of Potter sequence are a direct consequence of the low levels of amniotic fluid. These features include apparent hypertelorism, infraorbital creases, flattened nasal tip, hypoplastic mandible, enlarged and posteriorly rotated ears, redundant dry skin, genu varum, talipes, and metatarsus adductus. The lung volume is correspondingly small with a decrease in the number of airways and alveoli. Also, the size of the alveoli and the pulmonary arterioles are smaller than normal. 
Renal agenesis is the complete absence of one or both kidneys. This is separate from any disorder that has remnant or dysfunctional kidneys. Renal agenesis can present as early as 14 weeks with severe oligohydramnios. Up to $40 \%$ of infants with bilateral renal agenesis present with stillbirth with the remaining ones being premature and low birth weight. Of the live born infants all have respiratory distress due to pulmonary hypoplasia. Communicating structures in bilateral renal agenesis including complete absence of the ureters and hypoplasia, atresia or absence of the bladder are seen. In females, the vagina and uterus are absent or abnormal in $85 \%$ of cases (Gabow, 1993). In males, cryptorchidism and absence or abnormalities of the vas deferens and seminal vesicles are found. In severe cases penile agenesis or penoscrotal transposition have been seen.

Renal agenesis occurs from a defect in embryogenesis early in development (around day 35) or it may occur later as a result of a late occlusion of the renal artery causing involution of the kidney. Because renal agenesis may involve the Wolfian or Mullerian duct, defects of the urogenital sinus are seen together. This would explain the range of defects that involve anal anomalies, caudal and bladder extrophy. An even larger defect involves the entire caudal end of the embryo and result in caudal dysplasia or sirenomelia.

Unilateral renal agenesis may be incidentally discovered on a postnatal examination by palpating the enlarged or displaced remaining kidney or by ultrasound screening. Many individuals are asymptomatic but over $50 \%$ of remaining kidneys are found to have anomalies. Associated congenital defects are common. As expected in unilateral renal agenesis many of the defects are seen on the affected side. The ipsilateral uterus and Fallopian tube may be absent and the other uterine and vaginal ducts maybe present including the uterus didelphys (Li, Qayyum, Coakley, \& Hricak, 2000). Bladder extrophy, anal atresia, malrotation, Meckel's diverticulum and lumbosacral defects have been reported (Li, et al., 2000). Interestingly the ipsilateral adrenal gland is still found in its usual position unlike in bilateral renal agenesis where adrenal agenesis is common. Prognosis for isolated unilateral renal agenesis is quite good. The remaining kidney often compensates becoming hypertrophic and can have ureteral dilation with vesicoureteral reflux. Most infants that have unilateral renal agenesis are asymptomatic so do not develop pulmonary hypoplasia and therefore do not typically have respiratory problems at birth.

Bilateral renal agenesis is a universally fatal disorder. Of the remaining $60 \%$ who are not stillborn, death usually occurs within 24 hours from severe pulmonary hypertension from the pulmonary hypoplasia. There is no effective treatment. Amnio-infusion has been attempted to allow for lung growth but this has not been successful.

Other non-contiguous anomalies that are often seen in both bilateral and unilateral renal agenesis include limb deficiencies, tracheal agenesis, esophageal or duodenal atresia, cleft lip or palate, hydrocephalus and other brain malformations. Amnion nodosum of the placenta is seen as would be expected in oligohydramnios.

There are a number of acrorenal and cerebrorenal defects that are important to recognize. Acrorenal defects include defects that involve the limbs in addition to the kidneys. In particular the hands and feet are often abnormal and may include radial ray defects. Inheritance patterns are variable and some include chromosomal abnormalities as well. Cerebrorenal defects include brain and kidney and include disorders such as PHS, SLOS, and Meckel-Gruber syndrome (MGS). Both PHS and SLOS have been described earlier. 
(see 2.1.1.1 Pulmonary Agenesis/Aplasia) MGS is an autosomal recessive disorder and depending on its type is linked to a different chromosomal defect. Type I is linked to 17q22-q23, Type II is linked to 11q and Type III is linked to an 8q deletion (Morgan et al., 2002). The prominent features of MGS include occipital encephalocoele, other structural brain anomalies, ear anomalies, postaxial polydactyly, cleft lip and palate, ambiguous genitalia, biliary and pancreatic dysgenesis (Hsia, Bratu, \& Herbordt, 1971). The other renal anomalies can include duplicated ureters, hypoplastic bladder urethral atresia and if the kidneys are present they are often polycystic or dysplastic. This disease is uniformly fatal (Salonen, 1984).

There are also some well-known associations that may involve renal agenesis. CHARGE association stands for coloboma, heart defects, choanal atresia, mental retardation, genital hypoplasia, and ear anomalies. The genital anomalies include renal agenesis, dysplasia or ectopic duplication of the pelvis and ureter, megaureter and reflux. The prognosis depends on the degree of pulmonary hypoplasia as a result of bilateral or unilateral renal agenesis. The inheritance pattern is autosomal dominant with a deletion found on chromosome 8q12.1 (Vissers et al., 2004). MURCS association is an acronym for Mullerian duct aplasia, renal agenesis, and cervicothoracic somatic (vertebral) defects. They can also have a hypoplastic uterus, absent vagina, and short stature. Mutations are sporadic without any inheritance patterns. Prognosis for VACTERL association has been described earlier (see 2.1.1.1 Pulmonary Agenesis/Aplasia).

Renal agenesis also can be seen in over 30 chromosomal disorders including trisomy 13, 18 and 21 (Stevenson, 2006). (See 2.1.2.2.1 Congenital Diaphragmatic Hernia) It can also been found as a result of teratogen exposure in utero including alcohol, cocaine, diabetes, misoprostol, rubella virus, thalidomide, trimethadione, and warfarin (Stevenson, 2006).

Inheritance patterns can be heterogeneous. There have been familial cases of renal agenesis suggesting all types of inheritance as possibilities (Morse, Rawnsley, Crowe, Marin-Padilla, \& Graham, 1987). Isolated renal agenesis has been considered to be multifactorial with a low chance of recurrence in first-degree relatives.

\subsubsection{Inadequate thoracic space}

Another cause for development of secondary hypoplasia is the presence of space occupying lesions within the chest. This can be due to herniated bowel from a diaphragmatic hernia, cysts as in congenital cystic adenomatoid malformations, or a hydrothorax. There are a number of syndromes that are associated with each type of lesion and will be reviewed below.

\subsection{Congenital diaphragmatic hernia}

Congenital diaphragmatic hernia is the absence or underdevelopment of the tendinous or muscular parts of the diaphragm that allow abdominal contents to enter the thoracic cavity. The extrinsic compression of the lung by bowel secondarily results in pulmonary hypoplasia of both lungs with greatest impact on the affected lung (typically the left in $85 \%$ of cases). This pulmonary hypoplasia results in a pulmonary hypertension that is often resistant to medical therapy (Kinsella, Parker, Ivy, \& Abman, 2003). Congenital diaphragmatic hernia may be an isolated defect or associated with multiple malformations. Thirty-nine percent have nonpulmonary malformations (Cunniff, Jones, \& Jones, 1990). When congenital 
diaphragmatic hernia is associated with multiple anomalies it is associated with a poor outcome (Dillon, Renwick, \& Wright, 2000). Therefore identification of other anomalies when a diaphragmatic hernia is found is critical for prognosis. Fryns syndrome and Pallister-Killian syndrome must be considered in the differential diagnosis (See 2.1.1.1 Pulmonary Agenesis/Aplasia).

\subsection{Trisomy 13}

Trisomy 13 is a constellation of anomalies that include defects of the eye, nose lip, with forebrain abnormalities resulting in holoprosencephaly in association with polydactyly, narrow hyperconvex fingernails, and skin defects of the posterior scalp. Diaphragmatic defects are found in less than $50 \%$ of cases. A standard karyotype is sufficient to confirm the diagnosis.

\subsection{Trisomy 18}

Trisomy 18 is the second most common multiple malformation syndrome with an incidence of 0.3 per 100 newborn babies. There are over a 130 different abnormalities that have been reported in the literature (Jones \& Smith, 2006). Of the 10 percent of all congenital diaphragmatic hernias that have chromosomal abnormalities the most common is trisomy 18. The most common features of trisomy 18 are the clenched hands where there is overlapping of the index finger over the third, and the fifth finger over the fourth. They have a short sternum with reduced number of ossification centers, a prominent occiput with micrognathia, and a low arch dermal ridge pattern over six or more fingertips, with hypoplasia of the nails, especially on the fifth finger and toes. About 50 percent of babies with trisomy 18 die in the first week and many of the remaining die over the first year. The average survival time is only 14.5 days. A standard karyotype is sufficient to confirm the diagnosis.

\subsection{Cornelia de Lange syndrome}

Brachman-de Lange also known as Cornelia de Lange syndrome can also have diaphragmatic defects with diaphragmatic hernias or hiatal hernias. The syndrome has a characteristic facial feature of busy eyebrows and synophyrs with long curly eyelashes. Infants are initially hypertonic with a long philtrum, a thin downturning upper lip and micromelia of the upper and lower extremities. They have average intelligence quotients of 53 (Jones \& Smith, 2006). The natural history usually consists of failure to thrive, with feeding difficulties, hearing loss and speech delay. The syndrome is inherited in an autosomal dominant pattern and the mutation, Nipped-B homolog (NIPBL) is located on $5 \mathrm{p} 13$.

\subsection{Pallister-Killian syndrome}

Pallister-Killian syndrome is a dysmorphic condition involving most organ systems, but is also characterized by a tissue-limited mosaicism where most fibroblasts have 47 chromosomes with an extra small metacentric chromosome and the karyotype of lymphocytes is normal. The characteristic combination of clinical manifestations in this syndrome include coarse face, pigmentary skin anomalies, localized alopecia, profound mental retardation and seizures, and the relatively frequent occurrence of diaphragmatic defects and supernumerary nipples (Jones \& Smith, 2006). 


\subsection{Omphalocele}

An omphalocele is an abdominal wall defect whereby abdominal viscera are found centrally through a widened umbilical ring and generally covered with a membrane. The size of an omphalocele can vary tremendously but if giant it can result in a higher risk for PPHN. The mechanisms for this are not fully understood but may relate to reduced diaphragmatic function in the absence of most of the abdominal content. The presence of severe pulmonary morbidity is a notable distinguishing feature of omphaloceles in distinction to gastroschisis, another abdominal wall defect that is much less associated with PPHN. Associated conditions with giant omphaloceles include Beckwith-Wiedemann syndrome, Trisomy 13 (see 2.1.2.2.1.1 Trisomy 13), and limb-body wall complex. A case of omphalocele has been described in association with alveolar capillary dysplasia (Argyle, 1989; Hershenson et al., 1985). The limbbody wall complex is characterized by severe scoliosis, pulmonary hypoplasia, and giant omphalocele, the latter of which usually has an intact covering membrane, and sometimes a short umbilical cord, and should be distinguished from an isolated omphalocele because of its poor prognosis (Kamata, Usui, Sawai, Nose, \& Fukuzawa, 2008).

\subsection{Congenital Pulmonary Lymphangectasia}

Congenital pulmonary lymphangectasia (CPL) often presents with severe life threatening respiratory distress at birth. It is the congenital dilation of the superficial lymphatics of the pleura and septa and of the peribronchial and perivascular adventitia. The disease is characterized by inter-communicating, thin-walled, endothelium-lined, fluid-filled cysts of greatly varying diameter, situated in abundant subpleural, peribronchial, and interlobar connective tissue (Romano et al., 2010). The majority of infants are stillborn or die within the first 24 hours of life. Liveborn individuals typically develop acute respiratory distress with tachypnea, cyanosis, subcostal retractions, and prolonged expiration very soon after birth. Most medical therapies are not effective. On chest radiograph show large, punctate areas lesion throughout the lungs with Kerley B lines at the costophrenic angles, and overaeration of the lung fields with a flattened diaphragm but a normal sized heart. (Arkoff, 1968) These radiographic findings are useful for the clinician to differentiate CPL from meconium aspiration syndrome and pneumonia since these do not have Kerly B lines.

About $1 / 3$ to $1 / 2$ of all cases are associated with congenital heart defects particularly total anomalous pulmonary venous drainage, hypoplastic left heart syndrome, and premature closure of the foramen ovale. Both CPL and congenital heart defects together are part of asplenia and Noonan syndrome. Single cases have been reported with omphalocoele, malformation of the intestine, cretinism, arachnodactyly, trisomy 13, ureterovesical obstruction, Ehlers-Danlos syndrome, ichthyosis, cystic fibrosis, cystic hyperplasia of the bile ducts, and diaphragmatic hernia. There is a gender discrepancy with a male to female ratio of 2:1 (Fronstin, Hooper, Besse, \& Ferreri, 1967). Several sibling pairs have been reported (Scott-Emuakpor, Warren, Kapur, Quiachon, \& Higgins, 1981). Old case series of infants with CPL demonstrated a less than $25 \%$ survival. Those who survive suffer attacks of chronic respiratory distress cause by respiratory infections, with wheezing and coughing. Lobar pulmonary lymphangiectasia is cured by resection of the affected lobe. In the majority of cases treatment is usually palliative.

\subsection{Turner syndrome}

Turner syndrome is caused by abnormal chromosomal distribution leading to a $45, \mathrm{XO}$ individual. The most consistent features are short stature and gonadal dysgenesis. At birth 
about $80 \%$ have congenital lymphedema over the dorsum of the fingers and toes (Jones \& Smith, 2006). They often have a broad chest with widely spaced nipples that may be hypoplastic, inverted or both. Their facial features include prominent auricles, narrow maxillae, and an appearance of a short neck. Chromosomal testing will confirm the $45, \mathrm{XO}$ genotype.

\subsection{Noonan syndrome}

Prominent features of Noonan syndrome include short stature of postnatal onset, congenital heart defect, mental retardation, downward-slanting palpebrae, widely spaced eyes, ptosis, low nasal bridge, pectus deformity, webbed neck, strabismus, nystagmus, protruding upper lip, shield chest, cryptorchidism, other lymphatic abnormalities including hydrops, periperhal lymphedema, and chylous effusions (Allanson, 1987; Noonan, 1999; Witt et al., 1987). This syndrome has an autosomal dominant inheritance, but due to genetic heterogeneity, it occurs sporadically in families. It is frequently associated with pulmonary valve stenosis, hypertrophic cardiomypathy, atrial septal defect, tetralogy of Fallot, aortic coarctation, mitral valve anomalies, and atrioventricular canal (Glauser, Rorke, Weinberg, \& Clancy, 1990). Clinical course often includes poor feeding and gastrointestinal dysfunction, which can lead to failure to thrive. More severe feeding problems in infancy are may be associated with increased cognitive problems in childhood, but impairments are rarely severe.

\subsection{Congenital Cystic Adenoid Malformation}

Congenital Cystic Adenoid malformation (CCAM) is a pulmonary hamartomatous lesion composed of noncartilage-containing terminal respiratory structures resembling terminal bronchioles: There are three subtypes based on morphologies. The first, macrocystic (Type 1), occurs when there are one or more large cysts, between 2 and $10 \mathrm{~cm}$, that are predominately found. The cysts are lined by ciliated pseudostratified columnar epithelium, which occasionally produce mucin. Bronchiolar and alveolar elements are present between the cysts. The second are microcystic (Type 2), which have small uniform cysts, between 0.5 and $2 \mathrm{~cm}$ and are lined with cuboidal or columnar epithelium. The final type (Type 3) are solid in which an airless mass is found consisting of almost all bronchiolar and alveolar elements. On gross exam there are no cysts seen but there are microscopic alveolar cysts (Clements \& Warner, 1987). Diagnosis of CCAM is often now made on prenatal ultrasound. Respiratory symptoms can be present at birth and pulmonary hypertension can be seen secondary to either compression of the cysts or from rupture and resultant pneumothorax. Type 2 CCAM has the worst prognosis because they are often associated with other defects. In a series of prenatally diagnosed cases of microcystic lesions, bilateral lesion, or fetal hydrops were found, each were associated with a poor prognosis. However, polyhydramnios and mediastinal shift are not associated with a poor prognosis. In fact, there has been some series in which up to $56 \%$ of cases of CCAM have partially or complete regressed in utero (Laberge et al., 2001).

\subsection{Congenital Lobar Emphysema}

CLE is the most common congenital lesion of the lung parenchyma accounting for $50 \%$ of the lesions (Correia-Pinto, et al., 2010). Congenital lobar emphysema (CLE) occurs when there is hyperinflation of one or more lobes of the lung due to an intrinsic defect of the bronchopulmonary tree. Most newborns have respiratory distress with or without cyanosis. 
Chest asymmetry, decreased breath sounds, and mediastinal shift may be apparent on physical examination. Chest radiograph may initially show an opaque, fluid filled lobe, but follow-up films will eventually demonstrate overdistension and air trapping in the affected lobe with mediastinal shift and compression of the surrounding lung. Prenatally the diagnosis can be made with ultrasound or MRI. CLE only rarely presents with PPHN at birth (Schwartz \& Ramachandran, 1997). Concomitant cardiovascular disease however is not uncommon and should be investigated when CLE is detected (Dogan et al., 2004).

\subsubsection{Idiopathic pulmonary hypertension}

Some conditions that lead to PPHN are not based on obvious developmental abnormalities of the lung or pulmonary vasculature. Biochemical changes in the normal maintenance of pulmonary vascular tone may be responsible for these conditions. Some of these conditions illustrate the complex and delicate balance of ensuring normal pulmonary vascular function at birth and thereafter.

\subsubsection{Trisomy 21 (Down syndrome)}

Down syndrome (DS) is a chromosomal condition characterized by moderate impairment of cognitive ability and physical growth and a particular set of facial characteristics. They have microgenia (a small chin), an unusually round face, macroglossia, and almond shape of they eye caused by an epicanthic fold of the eyelid, upslanting palpebral fissures, short ribs, a single transverse palmar crease, poor muscle tone, and a larger than normal space between the first and second toes. The incidence of pulmonary hypertension in the newborn has been reported in one retrospective series to be as high as 6 percent of all Down syndrome births over a 4-year period (Cua, Blankenship, North, Hayes, \& Nelin, 2007). There have been a number of mechanisms to suggest how some neonates develop protracted pulmonary hypertension. One study demonstrated that DS patients might have an abnormal production of nitric oxide (NO) but respond appropriately to exogenous $\mathrm{NO}$ administration in the peripheral circulation (Cappelli-Bigazzi et al., 2004). Another study demonstrated less pulmonary vasodilation in response to $\mathrm{NO}$ in DS patients versus controls undergoing cardiac catheterization (Cannon et al., 2005). A genetic factor has been postulated to cause abnormal NO production resulting in an increased risk of PPHN. One study looked at the BMPR2 mutation, a gene mutation resulting in increase NO production and showed an increased occurrence in a subset of DS patients (Roberts et al., 2004). The mortality in DS overall is about $3.3 \%$ but is much higher $(5.8 \%$ versus $1.5 \%)$ in infants with congenital heart disease compared to those who do not (Weijerman et al., 2010). In a subset of 58 patients with Down syndrome there were 7 who met criteria for PPHN of which 2 died (Cua, et al., 2007). They did not have cardiac defects other than a PDA. There are no other long-term data on DS newborns with PPHN.

\subsubsection{Smith-Lemli-Opitz syndrome}

We have recently described a case of PPHN without obvious pulmonary hypoplasia in an infant with SLOS (Katheria, Masliah, Benirschke, Jones, \& Kim, 2010). In SLOS there is defect in cholesterol biosynthesis leading to abnormally low plasma cholesterol levels and elevated concentrations of the cholesterol precursor 7-dehydrocholesterol (7-DHC), the result of a deficiency of 7-DHC reductase. Disruptions in cholesterol metabolism can interrupt key signaling pathways that participate in the normal maintenance of pulmonary 
vascular tone. Others and we have found that caveolae-dependent signaling may be involved in this process since our patient had altered expression of caveolin- 1 suggesting that additional cellular alterations beyond mere changes associated with abnormal sterols in the membrane likely contribute to the pathogenesis of SLOS (Katheria, et al., 2010; Ren et al., 2011).

\subsection{Developmental disorders of pulmonary vasculature}

\subsubsection{Alveolar Capillary Dysplasia with Misalignment of the Pulmonary Veins (ACD/MPV)}

This pulmonary disorder is often found in newborns that are born full term with normal Apgar scores at birth and present with respiratory distress and cyanosis within the first 24 hours. The diagnosis is based on the failure of neonates to respond to conventional therapy and is confirmed on pathological evaluation. Histological features include a decreased number of alveolar capillaries, immature alveolar development, increased muscularization of pulmonary arterioles, and malposition of pulmonary vein branches adjacent to pulmonary artery branches. The pathogenesis of ACD/MPV is thought to be due to the failure of fetal lung vascularization to occur in response to some teratogen. This failure of vascularization forces blood to only be able to be drained via the pulmonary veins, which are malaligned. The obstruction that is created leads to the occlusive changes seen in the pulmonary arterial circulation. While the majority of cases have been sporadic events, there are about $10 \%$ of those that are found in siblings suggesting a heritable form of the disease (Langston, 1991). Extra-pulmonary findings are present in about 50 to $80 \%$ of cases (Sen, Thakur, Stockton, Langston, \& Bejjani, 2004). These include genitourinary, gastrointestinal, and cardiovascular systems. Also disruption of right-left symmetry has been reported in about $25 \%$ of cases (Sen, et al., 2004). It has also been seen in infants with Down syndrome (Sen, et al., 2004). There is no genetic test available, diagnosis is based on lung biopsy alone.

\subsubsection{Anomalous pulmonary veins}

Impairment of venous return to the left heart can result in inadequate blood flow through the pulmonary vasculature, which can predispose to pulmonary hypertension. Therefore any review of genetic causes of pulmonary hypertension must include cardiac conditions with anomalies of the pulmonary veins. Anomalies of the pulmonary veins can depend on the location, number and patency of the pulmonary veins. The main abnormalities are an abnormal pulmonary vein connection where one of more of the pulmonary veins connects to a systemic vein or to the right atrium. Absence of connections between the pulmonary veins and the left atrium is total anomalous pulmonary venous return (TAPVR). In partial anomalous pulmonary venous return (PAPVR), one to three of the pulmonary veins connects to the systemic veins. The most common abnormal connection is where the right pulmonary vein or veins connects into the superior or inferior vena cava. One candidate genetic locus with autosomal dominant inheritance of TAPVR involves the short arm of chromosome 4 and may be a vascular epithelial growth factor receptor, thought to have a role in vasculogenesis. No syndromic phenotype has been described for this defect however.

An anatomic variant of PAPVR is scimitar syndrome in which all or some of the right pulmonary veins enter the inferior vena cava at or below the level of the diaphragm. Other associated features of scimitar syndrome include right lung hypoplasia or horseshoe lung, 
secondary dextrocardia, hypoplasia of the right pulmonary artery, and pulmonary sequestration (Stevenson, 2006). Noncardiac malformations include vertebral anomalies, horseshoe kidneys and rectovaginal fistula. Scimitar syndrome can be diagnosed by the presence of a characteristic curvilinear pattern created on a chest radiograph by the pulmonary veins that drain to the inferior vena cava. Infants who present with Scimitar syndrome can develop pulmonary hypertension refractory to medical therapy requiring prompt cardiac surgery. However, infants often have postoperative pulmonary venous obstruction. There have been variations in survival reports in the literature with mortality rates ranging from 16 to $64 \%$ (Dupuis, Charaf, Breviere, \& Abou, 1993; Huddleston, Exil, Canter, \& Mendeloff, 1999; Huddleston \& Mendeloff, 1999).

Two other syndromes associated with partial anomalous venous return are Turner syndrome (See Turner Syndrome 2.1.2.2.3.1) and Holt-Oram syndrome. Holt-Oram syndrome or cardiac limb syndrome has an autosomal dominant inheritance pattern. The infants typically have malformation of the upper extremities. The thumbs may be absent, hypoplastic, thriphalangeal or bifid. Syndactyly often occurs between the thumb and the index finger. There may be dysplasia or aplasia of the radius or upper arm. There is a mutation on the TBX5 gene, which is linked to chromosome $12 \mathrm{q} 24.1$ in about $25 \%$ of familial cases and $50 \%$ of sporadic cases. There are no neurodevelopmental sequelae that have been reported. Outcome is dependent on the severity of the cardiac lesion.

In TAPVR, the pulmonary venous return to the systemic circulation may occur above the diaphragm, below the diaphragm or intracardiac. Two syndromes frequently associated with TAPVR are Cat eye syndrome and Smith Lemli Opitz syndrome. (see Smith Lemli Opitz syndrome, 2.1.3.2) Cat eye syndrome or coloboma of iris-anal atresia syndrome is hallmarked by the anal atresia and colobomata of the iris. The facies are characterized by hypertelorism, downslant of the palpebral fissures, with a low root of the nose. There may be pre-auricular tags and/or fistulas. Generally the colobomas are bilateral and they may have microphthalmos. However, only 9 of 100 reported cases had both features (Rosias et al., 2001). Cardiac defects are found in about $1 / 3$ of cases and can include in addition to TAPVR, persistence of the left superior vena cava, ventral septal defects (VSD), and atrial septal defects (ASD) (Schinzel et al., 1981). There is usually mild mental retardation although there have been some with reported normal intelligence but emotional disturbance problems. The etiology is a result of an extra chromosome derived from two identical segments of chromosome 22 or a tiny piece of the long arm of 22 (22pter; q11) (Jones \& Smith, 2006). Fluorescent in situ hybridization studies have been used successfully to document typical as well as atypical cases as well.

\subsubsection{Adams-Oliver syndrome (AOS)}

Adams-Oliver syndrome presents with aplasia cutis congenital, terminal transverse defects of limbs and in some cases severe pulmonary hypertension. Postmortem examination of an AOS patient with pulmonary hypertension showed defective vascular smooth muscle cell/pericyte coverage of the vasculature associated with 2 blood vessel abnormalities (Patel et al., 2004). Pericyte absence correlated with vessel dilatation whereas hyperproliferation of pericytes correlated with vessel stenosis. These findings suggested a unifying pathogenic mechanism for the abnormalities seen in AOS. 


\begin{tabular}{|l|l|}
\hline Condition & Defects \\
\hline Down Syndrome & $\begin{array}{l}\text { Congenital diaphragmatic hernia } \\
\text { Alveolar capillary hypoplasia } \\
\text { Renal agenesis }\end{array}$ \\
\hline Turner Syndrome & $\begin{array}{l}\text { Cystic hygroma } \\
\text { Anomalous pulmonary venous drainage }\end{array}$ \\
\hline Trisomy 18 & $\begin{array}{l}\text { Congenital diaphragmatic hernia } \\
\text { Renal agenesis }\end{array}$ \\
\hline Trisomy 13 & $\begin{array}{l}\text { Congenital diaphragmatic hernia } \\
\text { Renal agenesis } \\
\text { Omphalocele }\end{array}$ \\
\hline Smith-Lemli-Opitz Syndrome & $\begin{array}{l}\text { Pulmonary agenesis, abnormal lobulation } \\
\text { Primary pulmonary hypertension }\end{array}$ \\
\hline Fryns syndrome & $\begin{array}{l}\text { Congenital diaphragmatic hernia } \\
\text { Pulmonary agenesis, abnormal lobulation } \\
\text { Cystic hygroma }\end{array}$ \\
\hline
\end{tabular}

Table 1. Common conditions with multiple causes of PPHN

\subsection{Inborn errors}

\subsubsection{Introduction}

Single gene defects can lead to pulmonary under- or maldevelopment. Some causes are not associated with any obvious dysmorphisms and may be difficult to diagnose clinically aside for the severity of disease. The congenital surfactant deficiencies belong to one major class that lead to severe respiratory failure with severe PPHN.

\subsubsection{Congenital surfactant deficiencies}

Pulmonary surfactant is critical for postnatal adaptation of the newborn as it reduces the surface tension of the lung and prevents atelectasis that leads to lung injury. In fact, surfactant replacement therapy is one of the first therapies given to infants with PPHN to improve oxygenation. Surfactant is a complex of proteins and phospholipids in which each component is critical for a variety of functions. The protein components A, B, C, D make up about $10 \%$ by weight of pulmonary surfactant. We will review a number of mutations that are associated with disorders of pulmonary surfactant metabolism.

Neonates with defects in surfactant metabolism present can present acutely or in a more chronic and variable presentation. In the first presentation neonates develop respiratory failure shortly after birth that requires significant ventilator support and is minimally or transiently responsive to surfactant and often require extracorporeal membrane oxygenation (ECMO). Secondary pulmonary hypertension develops early and may only be partially responsive to inhaled NO. Chest $\mathrm{X}$-rays show a diffuse haziness mimicking respiratory distress syndrome (RDS). This presentation is typical of infants with mutations in SFTPB or ABCA3, but has also been occasionally seen in infants with mutation in SFTPC and NKX2.1 as well (Garmany et al., 2006; Nogee, Wert, Proffit, Hull, \& Whitsett, 2000; Shulenin et al., 2004). 
In the second less severe but variable presentation has been seen in infants with mutations in SFTPC, ABCA3 and NKX2.1. These children may present in the newborn period with milder respiratory symptoms that is often misdiagnosed as transient tachypnea of the newborn or congenital pneumonia and later develop a gradual onset of respiratory insufficiency, hypoxemia, failure to thrive and interstitial lung disease on chest radiographs. While some cases have a concurrent history of viral illnesses or aspiration, these features are not always consistent, suggesting that the variability in severity of the course of the disease is not dependent on the type of mutation making early accurate prognosis difficult.

\subsubsection{Surfactant protein-B deficiency}

Surfactant protein-B (SP-B) is a rare autosomal recessive disorder with an incidence of about 1 per million live births. Over 30 mutations in the SFTPB region have been identified resulting in partial to complete absence of the SP-B protein. The most common mutation, 121ins2, is associated with about 70\% of the cases of SP-B deficiency, and is most often found in those of European descent (Nogee, Wert, Proffit, Hull, \& Whitsett, 2000). The condition is lethal in the newborn period with the inability to oxygenation and ventilate and often infants are unable to come off ECMO successfully. SP-B deficiency has not been identified in infants less than 30 weeks gestation.

\subsubsection{2 АВСA3 deficiency}

ABCA3 is highly expressed in lung tissue, but also in the heart, brain, pancreas, kidneys and platelets. Similar to SP-B deficiency it is also autosomal recessive and when it presents in the acute form it is universally fatal. However it has also been seen in a chronic form often in premature infants whose respiratory dysfunction is more severe than would be anticipated for gestational age (Shulenin et al., 2004). This suggests that ABCA3 may be a marker for the risk as severity of RDS in newborns. Some studies suggest that ABCA3 deficiency may be the most common of the surfactant metabolism disorders. While the exact role of ABCA3 in surfactant metabolism is unknown, data from humans and mice suggest that ABCA3 mediates transport of phospholipids into lamellar bodies to produce surfactant. Disruption of this transport leads to reduce surfactant function.

\subsubsection{Surfactant protein-C disorders}

Surfactant protein-C (SP-C) is a lung is a lung specific protein that lowers the surface tension of the alveolae. The natural history is variable but less often presents as acute respiratory failure. The protein is encoded by the gene SFTPC in which about 35 different mutations have been described in both familial and sporadic cases (Brown, Dohm, Bernardino de la Serna, \& Barron, 2011). It can be inherited in an autosomal dominant pattern.

\subsubsection{Thyroid transcription factor}

Thyroid transcription factor is expressed in the brain, thyroid gland, and the lung and is critical for normal development. It has autosomal dominant inheritance and is expressed in the NKX2.1 gene and mutations present a constellation of hypothyroidism, choreoathetosis, and respiratory disease (Hamvas, 2010). The respiratory disease can manifest as RDS in the newborn period or as recurrent pulmonary infection or interstitial lung disease in later childhood. Similar to SFTPC about half the mutations are spontaneous. The natural history is variable. 
All of the surfactant disorders can be tested with genetic analysis for the various mutations, thereby avoiding more invasive testing such as lung biopsies. Diagnosis for these disorders is critical for prognosis and genetic counseling for future pregnancies. The only therapy for any of the surfactant disorders is lung transplant with a 5-year survival of only $50 \%$. Most of the short-term mortality is due to infection which in the long term accompanies other risks such as malignancies and the development of bronchiolitis obliterans. Even those who have survived the neonatal period have gross motor delays and need for nasogastric or gastrostomy feedings. The difficulties with the quality of life and excessive care these infants require prompt about half of the families eligible for transplantation to choose compassionate care for their infants.

\section{Conclusions}

The proper clinical diagnosis of pulmonary hypertension requires the integration of clinical, physiologic and echocardiographic information. Readily identifying accompanying clinical syndromes that are associated with severe PPHN is essential to making critical decisions on the extent and intensity of care. A sound knowledge of the pathophysiology of PPHN can help the clinician make sense of the varied presentations of PPHN particularly when syndromic features are recognized.

\section{References}

Abudu, O. O., Uguru, V., \& Olude, O. (1988). Contribution Of Congenital Malformation To Perinatal Mortality In Lagos, Nigeria. International Journal Of Gynaecology And Obstetrics, Vol.27, No.1, pp. 63-67, 0020-7292 (Print) 0020-7292 (Linking).

Aghabiklooei, A., Goodarzi, P., \& Kariminejad, M. H. (2009). Lung Hypoplasia And Its Associated Major Congenital Abnormalities In Perinatal Death: An Autopsy Study Of 850 Cases. Indian Journal Of Pediatrics, Vol.76, No.11, pp. 1137-1140, 0973-7693 (Electronic) 0019-5456 (Linking).

Allanson, J. E. (1987). Noonan Syndrome. Journal Of Medical Genetics, Vol.24, No.1, pp. 9-13, 0022-2593 (Print) 0022-2593 (Linking).

Argyle, J. C. (1989). Pulmonary Hypoplasia In Infants With Giant Abdominal Wall Defects. Pediatric Pathology, Vol.9, No.1, pp. 43-55, 0277-0938 (Print) 0277-0938 (Linking).

Arkoff, R. S. (1968). Congenital Pulmonary Lymphangiectasis. California Medicine, Vol.109, No.6, pp. 464-466, 0008-1264 (Print) 0008-1264 (Linking).

Brown, N. J., Dohm, M. T., Bernardino De La Serna, J., \& Barron, A. E. (2011). Biomimetic NTerminal Alkylation Of Peptoid Analogues Of Surfactant Protein C. Biophysical Journal, Vol.101, No.5, pp. 1076-1085, 1542-0086 (Electronic) 0006-3495 (Linking).

Burri, P. H. (2006). Structural Aspects Of Postnatal Lung Development - Alveolar Formation And Growth. Biology Of The Neonate, Vol.89, No.4, pp. 313-322, 0006-3126 (Print) 0006-3126 (Linking).

Cannon, B. C., Feltes, T. F., Fraley, J. K., Grifka, R. G., Riddle, E. M., \& Kovalchin, J. P. (2005). Nitric Oxide In The Evaluation Of Congenital Heart Disease With Pulmonary Hypertension: Factors Related To Nitric Oxide Response. Pediatric Cardiology, Vol.26, No.5, pp. 565-569, 0172-0643 (Print) 0172-0643 (Linking).

Cappelli-Bigazzi, M., Santoro, G., Battaglia, C., Palladino, M. T., Carrozza, M., Russo, M. G., Calabro, R. (2004). Endothelial Cell Function In Patients With Down's Syndrome. 
The American Journal Of Cardiology, Vol.94, No.3, pp. 392-395, 0002-9149 (Print) 00029149 (Linking).

Clements, B. S., \& Warner, J. O. (1987). Pulmonary Sequestration And Related Congenital Bronchopulmonary-Vascular Malformations: Nomenclature And Classification Based On Anatomical And Embryological Considerations. Thorax, Vol.42, No.6, pp. 401-408, 0040-6376 (Print) 0040-6376 (Linking).

Correia-Pinto, J., Gonzaga, S., Huang, Y., \& Rottier, R. (2010). Congenital Lung Lesions-Underlying Molecular Mechanisms. Seminars In Pediatric Surgery, Vol.19, No.3, pp. 171-179, 1532-9453 (Electronic) 1055-8586 (Linking).

Cua, C. L., Blankenship, A., North, A. L., Hayes, J., \& Nelin, L. D. (2007). Increased Incidence Of Idiopathic Persistent Pulmonary Hypertension In Down Syndrome Neonates. Pediatric Cardiology, Vol.28, No.4, pp. 250-254, 0172-0643 (Print) 0172-0643 (Linking).

Cunniff, C., Jones, K. L., \& Jones, M. C. (1990). Patterns Of Malformation In Children With Congenital Diaphragmatic Defects. The Journal Of Pediatrics, Vol.116, No.2, pp. 258261, 0022-3476 (Print) 0022-3476 (Linking).

Cunningham, M. L., \& Mann, N. (1997). Pulmonary Agenesis: A Predictor Of Ipsilateral Malformations. American Journal Of Medical Genetics, Vol.70, No.4, pp. 391-398, 0148-7299 (Print) 0148-7299 (Linking).

Dillon, E., Renwick, M., \& Wright, C. (2000). Congenital Diaphragmatic Herniation: Antenatal Detection And Outcome. The British Journal Of Radiology, Vol.73, No.868, pp. 360-365, 0007-1285 (Print) 0007-1285 (Linking).

Dogan, R., Dogan, O. F., Yilmaz, M., Demircin, M., Pasaoglu, I., Kiper, N., . . . Boke, E. (2004). Surgical Management Of Infants With Congenital Lobar Emphysema And Concomitant Congenital Heart Disease. The Heart Surgery Forum, Vol.7, No.6, pp. E644-649, 1522-6662 (Electronic) 1098-3511 (Linking).

Dupuis, C., Charaf, L. A., Breviere, G. M., \& Abou, P. (1993). "Infantile" Form Of The Scimitar Syndrome With Pulmonary Hypertension. American Journal Of Cardiology, Vol.71, No.15, pp. 1326-1330, 0002-9149 (Print) 0002-9149 (Linking).

Evans, J. A., Stranc, L. C., Kaplan, P., \& Hunter, A. G. (1989). Vacterl With Hydrocephalus: Further Delineation Of The Syndrome(S). American Journal Of Medical Genetics, Vol.34, No.2, pp. 177-182, 0148-7299 (Print) 0148-7299 (Linking).

Fewell, J. E., Lee, C. C., \& Kitterman, J. A. (1981). Effects Of Phrenic Nerve Section On The Respiratory System Of Fetal Lambs. Journal Of Applied Physiology: Respiratory, Environmental And Exercise Physiology, Vol.51, No.2, pp. 293-297, 0161-7567 (Print) 0161-7567 (Linking).

Fronstin, M. H., Hooper, G. S., Besse, B. E., \& Ferreri, S. (1967). Congenital Pulmonary Cystic Lymphangiectasis. Case Report And A Review Of 32 Cases. American Journal of Diseases Of Children, Vol.114, No.3, pp. 330-335, 0002-922x (Print) 0002-922x (Linking).

Fryns, J. P., Moerman, F., Goddeeris, P., Bossuyt, C., \& Van Den Berghe, H. (1979). A New Lethal Syndrome With Cloudy Corneae, Diaphragmatic Defects And Distal Limb Deformities. Human Genetics, Vol.50, No.1, pp. 65-70, 0340-6717 (Print) 0340-6717 (Linking).

Gabow, P. A. (1993). Autosomal Dominant Polycystic Kidney Disease. American Journal Of Kidney Diseases : The Official Journal Of The National Kidney Foundation, Vol.22, No.4, pp. 511-512, 0272-6386 (Print) 0272-6386 (Linking). 
Garmany, T. H., Moxley, M. A., White, F. V., Dean, M., Hull, W. M., Whitsett, J. A., Hamvas, A. (2006). Surfactant Composition And Function In Patients With Abca3 Mutations. Pediatric Research, Vol.59, No.6, pp. 801-805, 0031-3998 (Print) 0031-3998 (Linking).

Glauser, T. A., Rorke, L. B., Weinberg, P. M., \& Clancy, R. R. (1990). Congenital Brain Anomalies Associated With The Hypoplastic Left Heart Syndrome. Pediatrics, Vol.85, No.6, pp. 984-990, 0031-4005 (Print) 0031-4005 (Linking).

Hall, J. G., Pallister, P. D., Clarren, S. K., Beckwith, J. B., Wiglesworth, F. W., Fraser, F. C., Reed, S. D. (1980). Congenital Hypothalamic Hamartoblastoma, Hypopituitarism, Imperforate Anus And Postaxial Polydactyly--A New Syndrome? Part I: Clinical, Causal, And Pathogenetic Considerations. American Journal Of Medical Genetics, Vol.7, No.1, pp. 47-74, 0148-7299 (Print) 0148-7299 (Linking).

Hamvas, A. (2010). Evaluation And Management Of Inherited Disorders Of Surfactant Metabolism. Chinese Medical Journal, Vol.123, No.20, pp. 2943-2947, 0366-6999 (Print) 0366-6999 (Linking).

Hershenson, M. B., Brouillette, R. T., Klemka, L., Raffensperger, J. D., Poznanski, A. K., \& Hunt, C. E. (1985). Respiratory Insufficiency In Newborns With Abdominal Wall Defects. Journal Of Pediatric Surgery, Vol.20, No.4, pp. 348-353, 0022-3468 (Print) 0022-3468 (Linking).

Hsia, Y. E., Bratu, M., \& Herbordt, A. (1971). Genetics Of The Meckel Syndrome (Dysencephalia Splanchnocystica). Pediatrics, Vol.48, No.2, pp. 237-247, 0031-4005 (Print) 0031-4005 (Linking).

Huddleston, C. B., Exil, V., Canter, C. E., \& Mendeloff, E. N. (1999). Scimitar Syndrome Presenting In Infancy. The Annals Of Thoracic Surgery, Vol.67, No.1, pp. 154-159; Discussion 160, 0003-4975 (Print) 0003-4975 (Linking).

Huddleston, C. B., \& Mendeloff, E. N. (1999). Scimitar Syndrome. Advances In Cardiac Surgery, Vol.11, pp. 161-178, 0889-5074 (Print) 0889-5074 (Linking).

Jones, K. L., \& Smith, D. W. (2006). Smith's Recognizable Patterns Of Human Malformation (6th Ed.). Philadelphia: Elsevier Saunders.

Kallen, K., Mastroiacovo, P., Castilla, E. E., Robert, E., \& Kallen, B. (2001). Vater NonRandom Association Of Congenital Malformations: Study Based On Data From Four Malformation Registers. American Journal Of Medical Genetics, Vol.101, No.1, pp. 26-32, 0148-7299 (Print) 0148-7299 (Linking).

Kamata, S., Usui, N., Sawai, T., Nose, K., \& Fukuzawa, M. (2008). Prenatal Detection Of Pulmonary Hypoplasia In Giant Omphalocele. Pediatric Surgery International, Vol.24, No.1, pp. 107-111, 0179-0358 (Print) 0179-0358 (Linking).

Katheria, A. C., Masliah, E., Benirschke, K., Jones, K. L., \& Kim, J. H. (2010). Idiopathic Persistent Pulmonary Hypertension In An Infant With Smith-Lemli-Opitz Syndrome. Fetal And Pediatric Pathology, Vol.29, No.6, pp. 373-379, 1551-3823 (Electronic) 1551-3815 (Linking).

Khan, P. A., Cloutier, M., \& Piedboeuf, B. (2007). Tracheal Occlusion: A Review Of Obstructing Fetal Lungs To Make Them Grow And Mature. Journal Of Medical Genetics. Part C, Seminars In Medical Genetics, Vol.145c, No.2, pp. 125-138, 1552-4868 (Print) 1552-4868 (Linking).

Kinsella, J. P., Parker, T. A., Ivy, D. D., \& Abman, S. H. (2003). Noninvasive Delivery Of Inhaled Nitric Oxide Therapy For Late Pulmonary Hypertension In Newborn 
Infants With Congenital Diaphragmatic Hernia. The Journal Of Pediatrics, Vol.142, No.4, pp. 397-401, 0022-3476 (Print) 0022-3476 (Linking).

Knowles, S., Thomas, R. M., Lindenbaum, R. H., Keeling, J. W., \& Winter, R. M. (1988). Pulmonary Agenesis As Part Of The Vacterl Sequence. Archives Of Disease In Childhood, Vol.63, No.7 Spec No, pp. 723-726, 1468-2044 (Electronic) 0003-9888 (Linking).

Laberge, J. M., Flageole, H., Pugash, D., Khalife, S., Blair, G., Filiatrault, D., Wilson, R. D. (2001). Outcome Of The Prenatally Diagnosed Congenital Cystic Adenomatoid Lung Malformation: A Canadian Experience. Fetal Diagnosis And Therapy, Vol.16, No.3, pp. 178-186, 1015-3837 (Print) 1015-3837 (Linking).

Langston, C. (1991). Misalignment Of Pulmonary Veins And Alveolar Capillary Dysplasia. Pediatric Pathology, Vol.11, No.1, pp. 163-170, 0277-0938 (Print) 0277-0938 (Linking).

Li, S., Qayyum, A., Coakley, F. V., \& Hricak, H. (2000). Association Of Renal Agenesis And Mullerian Duct Anomalies. Journal Of Computer Assisted Tomography, Vol.24, No.6, pp. 829-834, 0363-8715 (Print) 0363-8715 (Linking).

Moessinger, A. C., Harding, R., Adamson, T. M., Singh, M., \& Kiu, G. T. (1990). Role Of Lung Fluid Volume In Growth And Maturation Of The Fetal Sheep Lung. The Journal Of Clinical Investigation, Vol.86, No.4, pp. 1270-1277, 0021-9738 (Print) 00219738 (Linking).

Morgan, N. V., Gissen, P., Sharif, S. M., Baumber, L., Sutherland, J., Kelly, D. A., Johnson, C. A. (2002). A Novel Locus For Meckel-Gruber Syndrome, Mks3, Maps To Chromosome 8q24. Human Genetics, Vol.111, No.4-5, pp. 456-461, 0340-6717 (Print) 0340-6717 (Linking).

Morse, R. P., Rawnsley, E., Crowe, H. C., Marin-Padilla, M., \& Graham, J. M., Jr. (1987). Bilateral Renal Agenesis In Three Consecutive Siblings. Prenatal Diagnosis, Vol.7, No.8, pp. 573-579, 0197-3851 (Print) 0197-3851 (Linking).

Narumi, Y., Kosho, T., Tsuruta, G., Shiohara, M., Shimazaki, E., Mori, T., Fukushima, Y. (2010). Genital Abnormalities In Pallister-Hall Syndrome: Report Of Two Patients And Review Of The Literature. American Journal Of Medical Genetics. Part A, Vol.152a, No.12, pp. 3143-3147, 1552-4833 (Electronic) 1552-4825 (Linking).

Nogee, L. M., Wert, S. E., Proffit, S. A., Hull, W. M., \& Whitsett, J. A. (2000). Allelic Heterogeneity In Hereditary Surfactant Protein B (Sp-B) Deficiency. American Journal Of Respiratory And Critical Care Medicine, Vol.161, No.3 Pt 1, pp. 973-981, 1073-449x (Print) 1073-449x (Linking).

Noonan, J. (1999). Noonan Syndrome--Then And Now. Cardiology In The Young, Vol.9, No.6, pp. 545-546, 1047-9511 (Print) 1047-9511 (Linking).

Page, D. V., \& Stocker, J. T. (1982). Anomalies Associated With Pulmonary Hypoplasia. The American Review Of Respiratory Disease, Vol.125, No.2, pp. 216-221, 0003-0805 (Print) 0003-0805 (Linking).

Patel, M. S., Taylor, G. P., Bharya, S., Al-Sanna'a, N., Adatia, I., Chitayat, D., Human, D. G. (2004). Abnormal Pericyte Recruitment As A Cause For Pulmonary Hypertension In Adams-Oliver Syndrome. American Journal Of Medical Genetics. Part A, Vol.129a, No.3, pp. 294-299, 1552-4825 (Print) 1552-4825 (Linking).

Ren, G., Jacob, R. F., Kaulin, Y., Dimuzio, P., Xie, Y., Mason, R. P., Tulenko, T. N. (2011). Alterations In Membrane Caveolae And $\mathrm{Bk}(\mathrm{Ca})$ Channel Activity In Skin 
Fibroblasts In Smith-Lemli-Opitz Syndrome. Mol Genet Metab, pp. 1096-7206 (Electronic) 1096-7192 (Linking).

Roberts, K. E., Mcelroy, J. J., Wong, W. P., Yen, E., Widlitz, A., Barst, R. J., Morse, J. H. (2004). Bmpr2 Mutations In Pulmonary Arterial Hypertension With Congenital Heart Disease. The European Respiratory Journal : Official Journal Of The European Society For Clinical Respiratory Physiology, Vol.24, No.3, pp. 371-374, 0903-1936 (Print) 0903-1936 (Linking).

Romano, A. A., Allanson, J. E., Dahlgren, J., Gelb, B. D., Hall, B., Pierpont, M. E., Noonan, J. A. (2010). Noonan Syndrome: Clinical Features, Diagnosis, And Management Guidelines. Pediatrics, Vol.126, No.4, pp. 746-759, 1098-4275 (Electronic) 0031-4005 (Linking).

Rosias, P. R., Sijstermans, J. M., Theunissen, P. M., Pulles-Heintzberger, C. F., De DieSmulders, C. E., Engelen, J. J., \& Van Der Meer, S. B. (2001). Phenotypic Variability Of The Cat Eye Syndrome. Case Report And Review Of The Literature. Genetic Counseling, Vol.12, No.3, pp. 273-282, 1015-8146 (Print) 1015-8146 (Linking).

Salonen, R. (1984). The Meckel Syndrome: Clinicopathological Findings In 67 Patients. American Journal Of Medical Genetics, Vol.18, No.4, pp. 671-689, 0148-7299 (Print) 0148-7299 (Linking).

Schinzel, A., Schmid, W., Fraccaro, M., Tiepolo, L., Zuffardi, O., Opitz, J. M., Pagon, R. A. (1981). The "Cat Eye Syndrome": Dicentric Small Marker Chromosome Probably Derived From A No.22 (Tetrasomy 22pter To Q11) Associated With A Characteristic Phenotype. Report Of 11 Patients And Delineation Of The Clinical Picture. Human Genetics, Vol.57, No.2, pp. 148-158, 0340-6717 (Print) 0340-6717 (Linking).

Schwartz, M. Z., \& Ramachandran, P. (1997). Congenital Malformations Of The Lung And Mediastinum--A Quarter Century Of Experience From A Single Institution. Journal Of Pediatric Surgery, Vol.32, No.1, pp. 44-47, 0022-3468 (Print) 0022-3468 (Linking).

Scott-Emuakpor, A. B., Warren, S. T., Kapur, S., Quiachon, E. B., \& Higgins, J. V. (1981). Familial Occurrence Of Congenital Pulmonary Lymphangiectasis. Genetic Implications. American Journal Of Diseases Of Children, Vol.135, No.6, pp. 532-534, 0002-922x (Print) 0002-922x (Linking).

Sen, P., Thakur, N., Stockton, D. W., Langston, C., \& Bejjani, B. A. (2004). Expanding The Phenotype Of Alveolar Capillary Dysplasia (Acd). Journal Of Pediatrics, Vol.145, No.5, pp. 646-651, 0022-3476 (Print) 0022-3476 (Linking).

Shulenin, S., Nogee, L. M., Annilo, T., Wert, S. E., Whitsett, J. A., \& Dean, M. (2004). Abca3 Gene Mutations In Newborns With Fatal Surfactant Deficiency. The New England Journal Of Medicine, Vol.350, No.13, pp. 1296-1303, 1533-4406 (Electronic) 0028-4793 (Linking).

Steinhorn, R. H. (2010). Neonatal Pulmonary Hypertension. Pediatric Critical Care, Vol.11, No.2 Suppl, pp. S79-84, 1529-7535 (Print) 1529-7535 (Linking).

Stevenson, R. E. (2006). Human Malformations And Related Anomalies (2nd Ed.). Oxford ; New York: Oxford University Press.

Vissers, L. E., Van Ravenswaaij, C. M., Admiraal, R., Hurst, J. A., De Vries, B. B., Janssen, I. M., Van Kessel, A. G. (2004). Mutations In A New Member Of The Chromodomain Gene Family Cause Charge Syndrome. Nature Genetics, Vol.36, No.9, pp. 955-957, 1061-4036 (Print) 1061-4036 (Linking). 
Weijerman, M. E., Van Furth, A. M., Van Der Mooren, M. D., Van Weissenbruch, M. M., Rammeloo, L., Broers, C. J., \& Gemke, R. J. (2010). Prevalence Of Congenital Heart Defects And Persistent Pulmonary Hypertension Of The Neonate With Down Syndrome. European Journal Of Pediatrics, Vol.169, No.10, pp. 1195-1199, 1432-1076 (Electronic) 0340-6199 (Linking).

Wigglesworth, J. S. (1981). Pulmonary Hypoplasia With Phrenic Nerve Agenesis. The Journal Of Pediatrics, Vol.98, No.4, pp. 667-668, 0022-3476 (Print) 0022-3476 (Linking).

Witt, D. R., Hoyme, H. E., Zonana, J., Manchester, D. K., Fryns, J. P., Stevenson, J. G., Hall, J. G. (1987). Lymphedema In Noonan Syndrome: Clues To Pathogenesis And Prenatal Diagnosis And Review Of The Literature. American Journal Of Medical Genetics, Vol.27, No.4, pp. 841-856, 0148-7299 (Print) 0148-7299 (Linking).

Zeltner, T. B., \& Burri, P. H. (1987). The Postnatal Development And Growth Of The Human Lung. Ii. Morphology. Respiration Physiology, Vol.67, No.3, pp. 269-282, 0034-5687 (Print) 0034-5687 (Linking). 


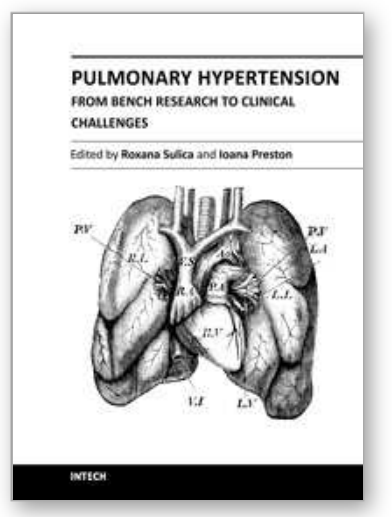

\section{Pulmonary Hypertension - From Bench Research to Clinical Challenges}

Edited by Dr. Roxana Sulica

ISBN 978-953-307-835-9

Hard cover, 326 pages

Publisher InTech

Published online 09, December, 2011

Published in print edition December, 2011

The textbook "Pulmonary Hypertension - From Bench Research to Clinical Challenges" addresses the following topics: structure and function of the normal pulmonary vasculature; disregulated cellular pathways seen in experimental and human pulmonary hypertension; clinical aspects of pulmonary hypertension in general; presentation of several specific forms of pulmonary hypertension, and management of pulmonary hypertension in special circumstances. The textbook is unique in that it combines pulmonary and cardiac physiology and pathophysiology with clinical aspects of the disease. First two sections are reserved for the basic knowledge and the recent discoveries related to structure and cellular function of the pulmonary vasculature. The chapters also describe disregulated pathways known to be affected in pulmonary hypertension. A special section deals with the effects of hypoxia on the pulmonary vasculature and the myocardium. Other three sections introduce the methods of evaluating pulmonary hypertension to the reader. The chapters present several forms of pulmonary hypertension which are particularly challenging in clinical practice (such as pulmonary arterial hypertension associated with systemic sclerosis), and lastly, they address special considerations regarding management of pulmonary hypertension in certain clinical scenarios such as pulmonary hypertension in the critically ill.

\section{How to reference}

In order to correctly reference this scholarly work, feel free to copy and paste the following:

Jae H. Kim and Anup Katheria (2011). Clinical Syndromes and Associations with Persistent Pulmonary Hypertension of the Newborn, Pulmonary Hypertension - From Bench Research to Clinical Challenges, Dr. Roxana Sulica (Ed.), ISBN: 978-953-307-835-9, InTech, Available from: http://www.intechopen.com/books/pulmonary-hypertension-from-bench-research-to-clinical-challenges/clinicalsyndromes-and-associations-with-persistent-pulmonary-hypertension-of-the-newborn

\section{INTECH}

open science | open minds

\section{InTech Europe}

University Campus STeP Ri

Slavka Krautzeka 83/A

51000 Rijeka, Croatia

Phone: +385 (51) 770447

Fax: +385 (51) 686166

\section{InTech China}

Unit 405, Office Block, Hotel Equatorial Shanghai

No.65, Yan An Road (West), Shanghai, 200040, China 中国上海市延安西路65号上海国际贵都大饭店办公楼 405 单元

Phone: +86-21-62489820

Fax: +86-21-62489821 
www.intechopen.com 
(C) 2011 The Author(s). Licensee IntechOpen. This is an open access article distributed under the terms of the Creative Commons Attribution 3.0 License, which permits unrestricted use, distribution, and reproduction in any medium, provided the original work is properly cited. 